\title{
Distribution, Sources and Risk Assessment of Microplastics in Sediments of an Urban Water Supply Reservoir, China
}

\section{Yunzhao Liu}

Anhui University - Qingyuan Campus

Zhongguan Jiang ( $\sim$ zhongguan6@163.com )

Anhui University

Jiajun Wu

Anhui University - Qingyuan Campus

Xianfu Zhao

Chinese Academy of Sciences

Jing Li

Anhui Academy of Agricultural Sciences

Ting Fang

Anhui Academy of Agricultural Sciences

Yangyang Liang

Anhui Academy of Agricultural Sciences

\section{Research Article}

Keywords: Microplastics, Water source areas, Sediments, Distribution, Ecological risks, Reservoirs

Posted Date: June 2nd, 2021

DOI: https://doi.org/10.21203/rs.3.rs-539528/v1

License: (a) (1) This work is licensed under a Creative Commons Attribution 4.0 International License.

Read Full License 


\section{Abstract}

In freshwater ecosystems, previous studies on microplastics have been mostly focused on natural rivers and lakes, with limited consideration of urban water source areas. Sediments, recording the steady process of microplastics accumulation during a long period of time, can act as an important sink for microplastics. In this study, we investigated the distribution, characteristics and ecological risks of microplastic contaminants in sediments of a water supply reservoir of Hefei City (the Dafangying Reservoir). Meanwhile, the differences of microplastic concentrations in sediments between the rural and urban areas were also compared. The average microplastics abundance of sediments in rural areas was $83.20 \pm 32.99 \mathrm{n} / 100 \mathrm{~g}$ dry weight $(\mathrm{dw})$, and $182.67 \pm 72.21 \mathrm{n} / 100 \mathrm{~g}(\mathrm{dw})$ in urban areas. The total microplastic concentrations were significantly higher in sediments of urban sites than that in rural sites ( $p$ $<0.01$ ), which can be ascribed to more complex and diverse microplastic sources triggered by intensive anthropogenic activity in cities. Specifically, we also demonstrated significantly higher microbead abundance $(p<0.01)$ in urban sites, which may result from the widespread use of microbead in personal care products. Our results detected five shapes (fibers, debris, films, foams and microbeads) and seven colors (white, black, transparency, red, blue, green and brown) of microplastics in sediments of the Dafangying Reservoir, with fibers and transparency accounting for the dominant shape and color, respectively. Given the complexity and diversity of microplastics in urban areas, we exhibited a relatively higher abundance of microplastics in the Dafangying Reservoir than that in other rural larger reservoirs. According to the index of geoaccumulation, the sedimentary microplastics were assessed as moderately polluted. Our study provides valuable references for microplastic contaminants in urban water supply reservoir, and highlights the importance of microplastics assessment in aquatic ecosystems.

\section{Introduction}

Microplastics, defining as plastic with diameter less than $5 \mathrm{~mm}$ (Arthur et al., 2009), has been widely recognized as a crucial environment problem (Blettler et al., 2017). The main sources of microplastic contaminants are the widespread use, improper management and disposal of plastic, such as the mishandling of plastic dropping and the emission of textile wastes (Alimi et al., 2018; Zhang et al., 2019). According to their sources, common microplastics can be divided into primary microplastics and secondary microplastics (Napper and Thompson, 2016). Plastics manufactured in microscopic sizes are defined as primary microplastics, e.g., microbeads of personal care products (Cole et al., 2011; Deng et al., 2020; Wagner et al., 2014). Secondary microplastics are decomposed from large plastics by physical degradation and biodegradation, e.g., abrasion and weathering (Arthur et al., 2009; Law and Thompson, 2014). Triggering by surface runoff, wind transport, rainfall and atmospheric inputs, a large amount of both primary and secondary microplastics will eventually enter into aquatic ecosystems, making the aquatic environments acting as a sink for microplastics (Bullard et al., 2020; Gatidou et al., 2018; Kane and Clare, 2019; Narmadha et al., 2020). Therefore, it is great significance for ecosystem to monitoring the occurrence and characteristics of microplastics in aquatic environments. 
In freshwater ecosystems, the assessment of microplastic contaminants has been mostly focused on natural rivers and lakes, with limited studies addressing the microplastics in urban water source areas (Blair et al., 2019; Vaughan et al., 2017; Wen et al., 2018). It has been reported that some sort of microplastics $(2.4 \pm 1.9 \mathrm{n} / \mathrm{L})$ were found in tap water, suggesting the potential pathway for microplastics from water source areas to human beings (Tong et al., 2020). Characterized by a larger specific surface area and strong hydrophobicity, microplastics act as enriched carriers of organic pollutants, heavy metals, and microbial pathogens, which can have adverse impacts in human bodies (Devriese et al., 2017; Ding et al., 2019; Kershaw, 2015; Zhou et al., 2020). Meanwhile, microplastics themselves can also cause particle toxicity, which can even induce an immune response (Koelmans et al., 2019). Consequently, for the benefits of human health, there is a pressing need to comprehensively explore and assess the microplastic pollutants in urban water source areas.

Suffering by high population density, with intensive anthropogenic activity, urban water source areas accept more intensified microplastics with multiple shapes and sources (Driedger et al., 2015; Floehr et al., 2013; Su et al., 2016). In urban areas, plentiful primary microplastics, used in personal care products to enhance the product properties, has finally discharged into aquatic environments by runoff from processing facilities or municipal sewage treatment plants (Cole et al., 2011; Fendall and Sewell, 2009; Klein et al., 2015). Besides, vast microplastics originating from the breakdown of larger plastic debris, preproduction pellets and the washing of synthetic textiles, also accounting for the specific microplastics sources in urban areas (Klein et al., 2015). It is worth noting that the washing artificial fabrics can lead to up to 1900 fibers discharging into wastewater per wash (Browne et al., 2011). In addition, airborne microplastics, in comprising of building materials and rubbish incineration can settle into the aquatic environments with rainfall (Lima et al., 2015; Zhang et al., 2020). Given the complexity and diversity of microplastics in urban areas, we hypothesized a more diverse and abundant microplastics in urban water source areas.

Traditionally, the sampling of microplastics has been implemented in surface and near-surface water, since most microplastics are recognized as present in the water layers (Kanhai et al., 2019). However, even microplastics (e.g., polyethylene and polypropylene) with density less than freshwater have also been frequently detected and concentrated in sediments (Coppock et al., 2017; Mao et al., 2020; Wen et al., 2018). In addition, microplastics appear more steadily in sediments than in water, and accumulate in sediments within a long period of time (Huang et al., 2020; Su et al., 2016). In consequence, sediments have recently been identified as an important sink for microplastics (Peng et al., 2017; Woodall et al., 2014). It has been recorded that about $70-90 \%$ of microplastics are accumulated into sediments in aquatic environments (Booth et al., 2016; Hammer et al., 2012). Moreover, with the process of seasonal hydrological regimes, microplastics in sediments may move from sinking to releasing (Ockelford et al., 2020), which can emit into the water layers and eventually pass through the food chain to humans (Ballent et al., 2016; Jambeck et al., 2015; Uddin et al., 2020). Clarifying the abundance and distribution of microplastics in sediments are the key reference for microplastics control. 
In this study, we investigated microplastic contaminations in sediments of the Dafangying Reservoir, which is the drinking water sources for Hefei city, with average annual water supply of 117 million $\mathrm{m}^{3}$. The Dafangying Reservoir is located in the transitional region between rural and urban areas in Hefei city. This study orientated to provide background information about the current situation of microplastic contaminations in sediments of the Dafangying Reservoir. The objectives of this study were as follows: (1) to investigate the concentration, distribution and characteristics of microplastics in sediments. (2) to explore whether there are significant differences for microplastics in sediments between the rural and urban areas. (3) to explore the ecological risks of microplastics in sediments of the Dafangying Reservoir.

\section{Materials And Methods}

\subsection{Study area and sampling sites}

The Dafangying Reservoir $\left(31^{\circ} 54^{\prime} \sim 31^{\circ} 58^{\prime} \mathrm{N} ; 117^{\circ} 13^{\prime} \sim 117^{\circ} 15^{\prime} \mathrm{E}\right.$ ), acting as a drinking water source in Hefei city, covers an area of $184 \mathrm{~km}^{2}$, which is mainly watered by rainfall and the surface runoff gathering in the Sili River. The Dafangying Reservoir is subjected to a subtropical monsoon climate, with mean annual air temperature of $15.7^{\circ} \mathrm{C}$, and mean annual precipitation of $975 \mathrm{~mm} / \mathrm{y}$. In August 2020, we selected 10 sampling sites evenly distributed across the Dafangying Reservoir to study the microplastic contaminants in sediments. For each sampling site, 3 replicates were randomly collected along the reservoir. According to the land use allocations of the Dafangying Reservoir, we classified all the sampling sites into two categories, i.e., the urban and rural sampling sites (Fig. 1). Sampling sites R1-R5, located at the west of the reservoir with rural land around, were identified as rural sites. Sampling sites U1-U5, located at the east of the reservoir with urban land around, were classified as urban sites.

\subsection{Sampling collection and processing}

Prior to sampling, all sampling tools, instruments and containers to be used were cleaned with ultrapure water. A cotton coat and nitrile gloves were won at all time during sampling. A total of 30 sediment samples were collected with a stainless-steel Peterson grab sampler (Xue et al., 2020). Then, we collected $0-5 \mathrm{~cm}$ of sediments on the surface with a stainless steel shovel and each sediment sample with a mass of approximate $1-2 \mathrm{~kg}$ (Deng et al., 2020). Sediment samples were stored in tin foil bags and then preserved at $4{ }^{\circ} \mathrm{C}$ before further analysis (Di and Wang, 2017; Su et al., 2016). Plastic materials were avoided throughout the whole sampling process.

\subsection{Microplastics extraction from sediment samples}

Microplastics were separated from the sediment using the method of separation by density conducted in Martins and Sobral (2011). Firstly, sediments were dried in oven $\left(60^{\circ} \mathrm{C}, 48 \mathrm{~h}\right)$ and then sieved through a 5 $\mathrm{mm}$ sieve (Jahan et al., 2019). Plastics $>5 \mathrm{~mm}$ were discarded. Secondly, $100 \mathrm{~g}$ of sediment (dw), $200 \mathrm{ml}$ $30 \% \mathrm{H}_{2} \mathrm{O}_{2}$ and $20 \mathrm{ml}$ of $0.05 \mathrm{M}$ ferrous sulfate heptahydrate $\left(\mathrm{FeSO}_{4} \cdot 7 \mathrm{H}_{2} \mathrm{O}\right)$ were added to a $1 \mathrm{~L}$ beaker (Peters et al., 2018). Then, saturated sodium chloride ( $\mathrm{NaCl}$ solution, $1.2 \mathrm{~g} / \mathrm{cm}^{3}$ ) were added to the beaker for $12 \mathrm{~h}$. Finally, the obtained solution was vacuum-filtered through a $0.45 \mu \mathrm{m}$ glass cellulose fiber 
membrane (GF/F, $47 \mathrm{~mm} \varnothing$, Whatman). The microplastics on the membrane were stored in a watch glass and dried in the oven at $50^{\circ} \mathrm{C}$ (Di and Wang, 2017).

\subsection{Microplastics observation and counting}

Microplastics were identified and quantified by a z-shaped pattern from left to right under a stereo microscope (Zhang et al., 2019). Selection of microplastics was implemented according to previously published guidelines (Hidalgo-Ruz et al., 2012; MERI, 2015). Microplastics were identified with the following criteria: size $<5 \mathrm{~mm}$, no cellular or organic structures visible, colored microplastics are homogeneous and are easy to distinguish, microplastics are difficult to break with tweezers. The number, shape (fibers, debris, films, foams and microbeads), color (white, black, transparency and colored), and size of the microplastics were recorded. The sizes of microplastics were divided into three classifications, $50 \mu \mathrm{m}-1 \mathrm{~mm}, 1-2 \mathrm{~mm}$ and 2-5 mm. Due to the limited aperture of filtration membrane, microplastics smaller than $50 \mu \mathrm{m}$ were not included in this study.

\subsection{Ecological risk assessment}

There is no widely accepted method to accurately assess the ecological risks of microplastics. In consistence with previous studies, we used the index of geoaccumulation (Igeo) to evaluate the ecological risk of microplastic contaminations. The index of geoaccumulation (Igeo) was first proposed by Muller (1969) and then developed by Forstner et al., (1990) to quantify the degree of metal contaminant in aquatic sediments. It can be calculated as follows,

$$
\text { Igeo }=\log _{2}\left(\frac{C_{n}}{1.5 \times B_{n}}\right)
$$

In this equation, $\mathrm{Cn}$ is the measured concentration in sediments and $B n$ is the background concentration in sediments (In this study, $B n$ is the mean concentrations of microplastics in sediments of fifteen lakes in the Yangtze River basin, $B n=21.9 \mathrm{n} / 100 \mathrm{~g}$ ), and 1.5 is a correction factor due to lithogenic effluents. The following classification is given for the Igeo values, the Igeo value $<0$ indicates practically unpolluted, the Igeo value within 0-1 indicates unpolluted to moderately polluted, the Igeo value within 1-2 indicates moderately polluted, the Igeo value within 2-3 indicates moderately to strongly polluted, the lgeo value within 3-4 indicates strongly polluted, the Igeo value within 4-5 indicates strongly to very strongly polluted, and the Igeo value $>5$ indicates very strongly polluted.

\subsection{Contamination control}

Precautions were taken to minimize contamination of the samples from airborne microplastics during processing. All containers and tools were washed before use and all containers containing samples were covered with aluminum foils. Researchers wore white cotton laboratory coats and nitrile gloves during all the processing. All of the purified water was filtered using a $0.45 \mu \mathrm{m}$ glass cellulose fiber membrane. Procedural blanks consisting of dampened membranes on the watch glass were used to check for background contamination from air in laboratory. We did not observe any microplastics in the procedural blanks. 


\subsection{Data analysis}

The means and standard deviations of the microplastics in sediments were calculated. One-way PERMANOVA (with 9999 permutations) analysis was used to evaluate whether the microplastics abundance and ecological risk significantly differed between rural sampling sites and urban sampling sites. Meanwhile, the abundance of each shape of microplastics was also tested between the rural and urban sampling sites. The level of significance was set at $p<0.05$. Microsoft Excel 2010 and software $R$ version 3.4.4 were used for processing and presenting data. Figures were drawn using ArcGIS 10.5 software, SigmaPlot 14.0 software and Origin 9 software.

\section{Results}

\subsection{Shapes and abundance of microplastics}

Our results detected five shapes of microplastics in sediments of the Dafangying Reservoir (i.e., fibers, debris, films, foams and microbeads). The examples and microscopic images of extracted microplastics were shown in Fig. 2. The average microplastics abundance of the urban sites was $182.67 \pm 72.21$ $\mathrm{n} / 100 \mathrm{~g}$, with the range of $65-390 \mathrm{n} / 100 \mathrm{~g}$. Fibers were dominant in sediment samples, accounting for $47.08 \%$, with the mean abundance of $86.00 \pm 82.57$. Microbeads also occurred frequently $(39.01 \%, 71.27$ $\pm 41.73)$, followed by debris $(11.17 \%, 20.40 \pm 26.48)$, films $(1.64 \%, 3.00 \pm 2.13)$ and foams $(1.09 \%, 2.00 \pm$ 2.76). As shown in Table 1, similar proportional gradient of different shapes of microplastics had been observed for the rural sites, i.e., fibers $(60.58 \%)>$ microbeads $(20.67 \%)>$ debris $(12.10 \%)$. Our results demonstrated significantly higher abundance of total microplastics and microbeads in the urban sites than that in rural sites (PERMANOVA, $p<0.01$ ). In comparison with larger natural lakes and reservoirs (e.g., TGR, PL and TL in Table 1), our results showed relatively higher microplastic concentrations. However, when comparing with urban rivers (e.g., PR and BR in Table 1), the microplastic concentrations in the Dafangying Reservoir exhibited relatively lower values.

\section{Table 1}

Microplastic concentrations per $100 \mathrm{~g}(\mathrm{dw})$ in the urban and rural sediments of the Dafangying Reservoir, and background microplastics abundance in other freshwater ecosystems of China. 


\begin{tabular}{|c|c|c|c|c|c|c|c|}
\hline & & $\begin{array}{l}\text { Total } \\
\text { (n/100g) }\end{array}$ & $\begin{array}{l}\text { Fibers } \\
(\mathrm{n} / 100 \mathrm{~g})\end{array}$ & $\begin{array}{l}\text { Debris } \\
\text { (n/100g) }\end{array}$ & $\begin{array}{l}\text { Films } \\
\text { (n/100g) }\end{array}$ & $\begin{array}{l}\text { Foams } \\
(\mathrm{n} / 100 \mathrm{~g})\end{array}$ & $\begin{array}{l}\text { Microbeads } \\
(\mathrm{n} / 100 \mathrm{~g})\end{array}$ \\
\hline \multirow[t]{3}{*}{ Rural } & $\begin{array}{l}\text { Mean } \pm \\
\text { SD }\end{array}$ & $\begin{array}{l}83.20 \pm \\
32.99\end{array}$ & $\begin{array}{l}50.40 \pm \\
28.88\end{array}$ & $\begin{array}{l}10.07 \pm \\
5.36\end{array}$ & $\begin{array}{l}2.20 \pm \\
1.90\end{array}$ & $\begin{array}{l}3.33 \pm \\
3.28\end{array}$ & $\begin{array}{l}17.20 \pm \\
10.48\end{array}$ \\
\hline & Range & $18-142$ & $8-106$ & $2-20$ & $0-6$ & $0-11$ & $0-36$ \\
\hline & Proportion & $100 \%$ & $60.58 \%$ & $12.10 \%$ & $2.64 \%$ & $4.01 \%$ & $20.67 \%$ \\
\hline \multirow[t]{3}{*}{ Urban } & $\begin{array}{l}\text { Mean } \pm \\
\text { SD }\end{array}$ & $\begin{array}{l}182.67 \pm \\
72.21\end{array}$ & $\begin{array}{l}86.00 \pm \\
82.57\end{array}$ & $\begin{array}{l}20.40 \pm \\
26.48\end{array}$ & $\begin{array}{l}3.00 \pm \\
2.13\end{array}$ & $\begin{array}{l}2.00 \pm \\
2.76\end{array}$ & $\begin{array}{l}71.27 \pm \\
41.73\end{array}$ \\
\hline & Range & $65-390$ & $14-355$ & $0-90$ & $0-8$ & $0-9$ & $16-154$ \\
\hline & Proportion & $100 \%$ & $47.08 \%$ & $11.17 \%$ & $1.64 \%$ & $1.09 \%$ & $39.01 \%$ \\
\hline Total & Proportion & $100 \%$ & $51.30 \%$ & $11.46 \%$ & $1.96 \%$ & $2.01 \%$ & $33.27 \%$ \\
\hline \multirow{2}{*}{$\begin{array}{l}\text { One-way } \\
\text { Permanova }\end{array}$} & $\mathrm{F}$ & 21.98 & 2.319 & 2.047 & 1.098 & 1.356 & 22.11 \\
\hline & P-value & 0.0001 & 0.128 & 0.2104 & 0.3494 & 0.28 & 0.0001 \\
\hline PR & Mean & 166.9 & $54.70 \%$ & $43.30 \%$ & $1.90 \%$ & $\mathrm{NL}$ & $\mathrm{NL}$ \\
\hline TGR & $\begin{array}{l}\text { Mean } \pm \\
\text { SD }\end{array}$ & $8.2 \pm 6$ & $71.00 \%$ & $15.00 \%$ & $\mathrm{NL}$ & $\mathrm{NL}$ & $10.00 \%$ \\
\hline PL & Mean & 113.4 & $3.31 \%$ & $74.00 \%$ & $15.46 \%$ & $\mathrm{NL}$ & $\mathrm{NL}$ \\
\hline TL & Range & $\begin{array}{l}1.1- \\
23.46\end{array}$ & $\mathrm{NL}$ & NL & $\mathrm{NL}$ & NL & $\mathrm{NL}$ \\
\hline BR & $\begin{array}{l}\text { Mean } \pm \\
\text { SD }\end{array}$ & $\begin{array}{l}160 \pm \\
19.1\end{array}$ & NA & NA & NA & NA & NA \\
\hline
\end{tabular}

NA is Not Analyzed, NL is Not Listed.

PR is Pearl River (Lin et al., 2018), TGR is the Three Gorges Reservoir (Di and Wang, 2017), PL is the Poyang Lake (Liu et al., 2019), TL is the Taihu Lake (Su et al., 2016), BR is Beishagang River (Peng et al., 2017).

\subsection{Size distribution of microplastics}

Microplastics were classified into three categories according to the size, $50 \mu \mathrm{m}-1 \mathrm{~mm}, 1-2 \mathrm{~mm}, 2-5 \mathrm{~mm}$. Microplastics with $50 \mu \mathrm{m}-1 \mathrm{~mm}$ accounting for the majority $(91.17 \%)$ of all the sizes, followed by those in $1-2 \mathrm{~mm}(7.50 \%)$ and $2-5 \mathrm{~mm}(1.33 \%)$, respectively. In size ranges of $50 \mu \mathrm{m}-1 \mathrm{~mm}$, fibers $(43.08 \%)$ were the dominant shape, followed by microbeads (33.27\%), debris (11.36\%), foams $(2.01 \%)$ and films $(1.45 \%)$. In the other two size categories, however, fibers accounted for almost all of the microplastics. 


\subsection{Color distribution of microplastics}

Seven colors of microplastics, including white, black, transparency, red, blue, green and brown, were observed in sediments of the Dafangying Reservoir. Transparency (49.22\%) was the most common microplastics color. White ones took second place (28.41\%), followed by black (18.66\%) and colored (3.71\%). In colored microplastics, blue was the most prevalent (56.76\%), followed by brown (22.97\%), red $(17.57 \%)$ and green $(2.70 \%)$. Most fibers, films, foams and microbeads were white or transparent, while debris was predominantly black.

\subsection{Ecological risk assessment}

The Igeo values for the study area were presented in Table 2 . The Igeo values ranged from 0.8 to 1.76 in rural sites, and 1.89 to 2.55 in urban sites. The contamination of microplastics was relatively higher in urban sites than in rural sites. Our results demonstrated significantly higher ecological risk (Igeo values) of microplastics in urban sites than that in rural sites (Fig. 6, PERMANOVA, $p<0.01$ ). According to the Igeo values classification, the sediments in the rural areas were assessed as unpolluted to moderately polluted. However, sampling sites located in the urban areas fluctuated from moderately to strongly polluted. To sum up, given the averaged Igeo values for both the rural and urban areas, the Dafangying Reservoir were identified as moderately polluted.

\section{Table 2}

Igeo assessment data of microplastics in the Dafangying Reservoir and their classes.

\begin{tabular}{|lllll|}
\hline Land Use & Sample sites & Igeo & Class & Predicted level of risk \\
\hline Rural & R1 & 1.76 & $1-2$ & moderately polluted \\
& R2 & 1.34 & $1-2$ & moderately polluted \\
\hline & R3 & 1.38 & $1-2$ & moderately polluted \\
\hline R4 & 1.27 & $1-2$ & moderately polluted \\
\hline Rrban & U1 & 0.80 & $0-1$ & unpolluted to moderately polluted \\
\hline U2 & 2.54 & $2-3$ & moderately to strongly polluted \\
\hline U3 & 2.42 & $2-3$ & moderately to strongly polluted \\
\hline U4 & 2.51 & $2-3$ & moderately to strongly polluted \\
\hline Average & 2.55 & $2-3$ & moderately to strongly polluted \\
\hline SD is the standard deviation. & 2.34 & $2-3$ & moderately to strongly polluted \\
\hline
\end{tabular}




\section{Disscussion}

\subsection{Shapes and abundance of microplastics}

Microplastics collected in the Dafangying Reservoir were rich in shapes, including fibers, debris, films, foams and microbeads. Fibers were the dominant shape, accounting for $51.30 \%$ in sediment samples of the Dafangying Reservoir. The dominant situation of fibers abundance was in accordance with many previous works. Di and Wang (2017) recorded the dominant appearance of fibers, accounting for 33.9$100 \%$ of all shapes (i.e., fiber, fragment, pellet, film and foam) across all the sediment samples of the Three Gorges Reservoir. Su et al., (2016) also found that fibers are dominant at $48-84 \%$ of all four shapes (i.e., fiber, pellet, film and fragment) in Taihu Lake. Moreover, they ascribed the main sources of microplastics in the Three Gorges Reservoir and Taihu Lake to washing sewage containing fibers and degradation of fishing nets. Previous results estimated that reference load of $6 \mathrm{~kg}$ of synthetic fibers discharge an average rate of $1.8 \cdot 10^{7}$ synthetic microfibers (Galvao et al., 2020). The dominant contamination of fibers in the Dafangying Reservoir may result from the washing of synthetic textiles, since fibers cannot be effectively removed by wastewater (Leslie et al., 2017).

Our results demonstrated significantly higher abundance of total microplastics and microbeads for sediments in urban areas than in rural areas, suggesting the tight correlation between the microplastic pollutions and land use. In consistence with our results, Huang et al., (2020) found higher abundance of microplastics in sediments located closely to urban areas. As hypothesized, the significantly higher microplastic contaminants in urban sediments can be ascribed to three unique pathways derived from cities. Firstly, the booming consumption of plastics products (e.g., clothing and packing) triggered by high population density in cities can provide a higher sources of microplastics, which leads to a higher risk of microplastics emissions of the urban water environments (Yin et al., 2019; Zhang et al., 2015). Secondly, the more frequent usage of building materials and tires in cities, incur more microplastics flowing into the urban aquatic ecosystems through the weather factors (e.g., rainfall, snowfall and wind) and overland runoff (Chen et al., 2020; Unice et al., 2019). Finally, the wide use of microbeads in facial cleansers instead of natural exfoliating materials can result in significantly higher microbead pollutants in urban areas (Sun et al., 2019).

In sediments of the Dafangying Reservoir, debris, also accounted for a certain proportion of abundance, while films and foams for small proportions of the total microplastics. Our results were lower in debris $(11.46 \%)$ in contrast with previous studies (debris, 43.3\%) in sediments of Pearl River along Guangzhou city (Lin et al., 2018). Debris was mainly originated from the breakdown of large plastic products, such as plastic packing bags and plastic containers (Thompson et al., 2004). Due to the lower surface to volume ratio, debris can easily sink and deposit in sediments (Wang et al., 2017). In contrast, due to the low density, films and foams can hardly sink or deposit in sediments of aquatic ecosystems (Vaughan et al., 2017; Vianello et al., 2013). In consequence, films (1.96\%) and foams (2.01\%) accounted for the smallest proportions in sediments of the Dafangying Reservoir. Similarly, Di and Wang (2017) also recorded the lower abundance of the Three Gorges Reservoir. 


\subsection{Size distribution of microplastics}

In consistence of previous studies, the proportion of microplastics items decreased with increased size category (Lenaker et al., 2019; Pazos et al., 2018). Previous study on the Tibetan plateau reported that more than $70 \%$ of microplastics were $<1 \mathrm{~mm}$ (Jiang et al., 2019). Similarly, the most common particle size in this study dropped into the range of $50 \mu \mathrm{m}-1 \mathrm{~mm}$, which covers all five shapes of microplastics. Within the size ranges of $50 \mu \mathrm{m}-1 \mathrm{~mm}$, fibers accounted for the largest proportion, followed by microbeads. The dominant size of fibers in this study were supported by the investigation of washing wastewater, in which $96 \%$ of the fibers were in the range of 50-500 $\mu \mathrm{m}$ (Galvao et al., 2020). Meanwhile, the mainly source of microbeads originated from personal care products are also produced in the range size of 1-800 $\mu \mathrm{m}$ in the factory (Sundt et al., 2014). The other two microplastic sizes (i.e., 1-2 $\mathrm{mm}$ and 2-5 mm), were almost occupied by fibers. The large-sized fibers can randomly degrade into smaller size, suggesting a variety of size ranges from a series of break (Li et al., 2019). Zhou et al., (2020) detected seven classes of microplastics (range from 50 to $5000 \mu \mathrm{m}$ ) in mangrove sediments of southeast of China, with fibers comprehensively presenting in all classes.

\subsection{Color distribution of microplastics}

Transparency, white and black accounted for the most colors (96.29\%) of microplastics in sediments of the Dafangying Reservoir. The high proportion of colorless microplastics (i.e., transparency and white) in this study was in line with that (i.e., transparency $38 \%$ and white $28 \%$ ) in sediments of Maozhou River (Wu et al., 2020). Campanale et al., (2019) also found that transparency was the most common color (56\%) in microplastics, which was followed by black (35\%). Meanwhile, indicating from a review of 14 studies in lake ecosystems, Zhang et al., (2018) found transparent microplastics were concurrently dominant in all these inland basins of China. The higher frequency of white and transparency can be explained by the fading process through UV light and weathering, and some microplastics (e.g., fibers and microbeads), were intentional produced in white or transparency (Wagner and Lambert, 2018). In colored microplastics, blue was the most prevalent, followed by brown, red and green. Similarly, besides the colorless $(37.8 \%)$ and black (26.2\%) microplastics, Baldwin et al., (2020) also found the higher proportion of blue (24.3\%) in colored microplastics in sediments of Lake Mead.

\subsection{Compare with other regions}

The microplastic concentrations in our study are relatively higher than that in rural reservoirs such as the Huangjinxia Reservoir ( $82 \pm 60 \mathrm{n} / \mathrm{kg}$ ) and the Three Gorges Reservoir (558.10 $\pm 291.45 \mathrm{n} / \mathrm{kg})$ (Di and Wang, 2017; Li et al., 2020). In comparation with the Dafangying Reservoir in Hefei City, the Huangjinxia Reservoir is located in the low-density population areas with slight anthropogenic activity, thus lower microplastics and no microbeads were recorded in their study. Whereas, the hydrologic exchange of water and the dilution effect of the large areas in the Three Gorges Reservoir result in relatively lower microplastics concentration than that in the Dafangying Reservoir. However, when comparing with urban drainage basins, our results demonstrated relatively lower abundance of microplastics than that in sediments of Nakdong River, South Korea (i.e., 1970 n/kg; Eo et al., 2019). The index of geoaccumulation 
was calculated in this study to assess ecological risk. According to Igeo values classification, sampling sites in the rural areas were assessed as unpolluted to moderately polluted. Nevertheless, all sediments in the urban areas fluctuated from moderately to strongly polluted. In general, microplastics contamination in the Dafangying Reservoir was moderately polluted.

\section{Conclusion}

Microplastics were detected in all sediment samples from the Dafangying Reservoir, with the average microplastics abundance of $83.20 \pm 32.99 \mathrm{n} / 100 \mathrm{~g}$ in rural sites and $182.67 \pm 72.21 \mathrm{n} / 100 \mathrm{~g}$ in urban sites. The abundance of total microplastics and microbeads were significantly higher in urban sediments than that in rural sediments. This phenomenon can be explained by the particular origins of plastics in cities, including the vast consumption of plastics products (e.g., plastic bags and plastic containers), frequent usage of building materials and tires, widely annexing of microbeads in facial cleansers. Meanwhile, fibers accounted for the main shape of microplastics, since the washing of synthetic textiles can lead to larger amount of fibers discharging into the aquatic ecosystems (Browne et al., 2011; Klein et al., 2015). In addition, due to the fading process through weathering and the intentional produced colorless plastics, transparency possessed the predominant color in sediments of the Dafangying Reservoir. Generally, indicating from Igeo values, microplastics contamination in the Dafangying Reservoir was assessed moderately polluted, advocating a pressing need for further studies to trance the control of microplastic contaminants in aquatic ecosystems.

\section{Declarations}

\section{Ethics approval and consent to participate}

Not applicable.

\section{Consent for publication}

Not applicable.

\section{Availability of data and materials}

The datasets used and/or analysed during the current study are available from the corresponding author on reasonable request.

\section{Competing interests}

The authors declare that they have no competing interests.

\section{Funding}

National Key Research and Development Program of China. 
Key Foundation of Anhui Province Education Department.

National Natural Science Foundation of China.

Key Research and Development Projects of Anhui Province.

Innovation Team of Wetland Ecology and Applied Technology, Anhui Academy of Agricultural Sciences.

\section{Authors' contributions}

YZL: Methodology, Formal analysis, Writing - original draft, Visualization; ZGJ: Conceptualization, Writing original draft, Supervision, Project administration; JJW: Investigation, Formal analysis; XFZ:

Conceptualization, Methodology, Funding acquisition; JL: Investigation, Data curation, Visualization; TF: Methodology, Software, Resources; YYL: Investigation, Resources.

\section{Acknowledgments}

This work was financially supported by the National Key Research and Development Program of China (No. 2017YFC0405303), the Key Foundation of Anhui Province Education Department (No. KJ2020A0045), the National Natural Science Foundation of China (No. 31600438), Key Research and Development Projects of Anhui Province (No. 202004i07020007), Innovation Team of Wetland Ecology and Applied Technology, Anhui Academy of Agricultural Sciences (No. 2021YL055). Thanks are given to Chang Xie, Xin Chen and Xiaowei Yin for their help during the experimentation.

\section{References}

Alimi O.S., Budarz J.F., Hernandez L.M., Tufenkji N., 2018. Microplastics and nanoplastics in aquatic environments: Aggregation, deposition, and enhanced contaminant transport. Environ. Sci. Technol. 52, 1704-1724. https://doi.org/10.1021/acs.est.7b05559. Arthur C., Baker J., Bamford H., 2009. Proceedings of the international research workshop on the occurrence, effects, and fate of microplastic marine debris. NOAA. Baldwin A.K., Spanjer A.R., Rosen M.R., Thom T., 2020. Microplastics in Lake Mead National Recreation Area, USA: Occurrence and biological uptake. Plos One 15, e0228896.

https://doi.org/10.1371/journal.pone.0228896. Ballent A., Corcoran P.L., Madden O., Helm P.A., Longstaffe F.J., 2016. Sources and sinks of microplastics in Canadian Lake Ontario nearshore, tributary and beach sediments. Mar. Pollut. Bull. 110, 383-395. https://doi.org/10.1016/j.marpolbul.2016.06.037 Blair R.M., Waldron S., Phoenix V.R., Gauchotte-Lindsay C., 2019. Microscopy and elemental analysis characterisation of microplastics in sediment of a freshwater urban river in Scotland, UK. Environ. Sci. Pollut. R. 26, 1249112504. https://doi.org/10.1007/s11356-019-04678-1. Blettler M.C.M., Ulla M.A., Rabuffetti A.P., Garello N., 2017. Plastic pollution in freshwater ecosystems: Macro-, meso-, and microplastic debris in a floodplain lake. Environ. Monit. Assess. 189, 581. https://doi.org/10.1007/s10661-017-6305-8. Booth A.M., Hansen B.H., Frenzel M., Johnsen H., Altin D., 2016. Uptake and toxicity of methylmethacrylate-based nanoplastic particles in aquatic organisms. Envir. Toxicol. Chem. 35, 1641-1649. https://doi.org/10.1002/etc.3076. Browne M.A., Crump P., Niven S.J., Teuten E., Tonkin A., Galloway T., Thompson R., 2011. Accumulation of 
microplastic on shorelines woldwide: Sources and sinks. Environ. Sci. Technol. 45, 9175-9179. https://doi.org/10.1021/es201811s. Bullard J.E., Ockelford A., O'Brien P., Neuman C.M., 2020. Preferential transport of microplastics by wind. Atmos. Environ. 245, 118038.

https://doi.org/10.1016/j.atmosenv.2020.118038. Campanale, C., Stock F., Massarelli C., Kochleus C., Bagnuolo G., Reifferscheid G., Uricchio V.F., 2019. Microplastics and their possible sources: The example of Ofanto River in southeast Italy. Environ. Pollut. 258, 113284.

https://doi.org/10.1016/j.envpol.2019.113284. Chen H., Jia Q.L., Zhao X., Li L., Nie Y.H., Liu H., Ye J.F., 2020. The occurrence of microplastics in water bodies in urban agglomerations: Impacts of drainage system overflow in wet weather, catchment land-uses, and environmental management practices. Water Res. 183, 116073. https://doi.org/10.1016/j.watres.2020.116073. Cole M., Lindeque P., Halsband C., Galloway T.S., 2011. Microplastics as contaminants in the marine environment: A review. Mar. Pollut. Bull. 62, 2588-2597. https://doi.org/10.1016/j.marpolbul.2011.09.025. Coppock R.L., Cole M., Lindeque P.K., Queiros A.M., Galloway T.S., 2017. A small-scale, portable method for extracting microplastics from marine sediments. Environ. Pollut. 230, 829-837. https://doi.org/10.1016/j.envpol.2017.07.017. Deng H., Wei R., Luo W.Y., Hu L.L., Li B.W., Shi H.H., 2020. Microplastic pollution in water and sediment in a textile industrial area. Environ. Pollut. 258, 113658. https://doi.org/10.1016/j.envpol.2019.113658. Devriese L.I., De Witte B., Vethaak A.D., Hostens K., Leslie H.A., 2017. Bioaccumulation of PCBs from microplastics in Norway lobster (nephrops norvegicus): An experimental study. Chemosphere. 186, 10-16. http://doi.org/10.1016/j.chemosphere.2017.07.121. Di M.X., Wang J., 2017. Microplastics in surface waters and sediments of the Three Gorges Reservoir, China. Sci. Total Environ. 616, 1620-1627. https://doi.org/10.1016/j.scitotenv.2017.10.150. Ding L., Mao R.F., Guo X.T., Yang X.M., Zhang Q., Yang C., 2019. Microplastics in surface waters and sediments of the Wei River, in the northwest of China. Sci. Total Environ. 667, 427-434. https://doi.org/10.1016/j.scitotenv.2019.02.332. Driedger A.G.J., Durr H.H., Mitchell K., Van Cappellen P., 2015. Plastic debris in the Laurentian Great Lakes: A review. J. Great Lakes Res. 41, 919. https://doi.org/10.1016/j.jglr.2014.12.020. Eo S., Hong S.H., Song Y.K., Han G.M., Shim W.J., 2019. Spatiotemporal distribution and annual load of microplastics in the Nakdong River, South Korea. Water Res. 160, 228-237. https://doi.org/10.1016/j.watres.2019.05.053. Fendall L.S., Sewell M.A., 2009. Contributing to marine pollution by washing your face: Microplastics in facial cleansers. Mar. Pollut. Bull. 58, 1225-1228. https://doi.org/10.1016/j.marpolbul.2009.04.025. Floehr T., Xiao H.X., Scholz-Starke B., Wu L.L., Hou J.L., Yin D.Q., Zhang X.W., Ji R., Yuan X.Z., Ottermanns R., Ross-Nickoll M., Schaffer A., Hollert H., 2013. Solution by dilution?-A review on the pollution status of the Yangtze River. Environ. Sci. Pollut. R. 20, 6934-6971. https://doi.org/10.1007/s11356-013-1666-1. Forstner U., Ahlf W., Calmano W., Kersten M., 1990. Sediment criteria development. Sediments and Environmental Geochemistry. 311-338.

https://doi.org/10.1007/978-3-642-75097-7_18. Galvao A., Aleixo M., De Pablo H., Lopes C., Raimundo J., 2020. Microplastics in wastewater: Microfiber emissions from common household laundry. Environ. Sci. Pollut. R. 27, 26643-26649. https://doi.org/10.1007/s11356-020-08765-6. Gatidou G., Arvaniti O.S., Stasinakis A.S., 2018. Review on the occurrence and fate of microplastics in sewage treatment plants. J. Hazard. Mater. 367, 504-512. https://doi.org/10.1016/j.jhazmat.2018.12.081. Hammer J., Kraak M.H.S., Parsons J.R., 2012. Plastics in the marine environment: The dark side of a modern gift. Rev. Environ. Contam. T. 220, 1-44. https://doi.org/10.1007/978-1-4614-3414-6_1. Hidalgo-Ruz V., Gutow L., Thompson 
R.C., Thiel M., 2012. Microplastics in the marine environment: A review of the methods used for identification and quantification. Environ. Sci. Technol. 46, 3060-3075.

https://doi.org/10.1021/es2031505. Huang D.F., Li X.Y., Ouyang Z.Z., Zhao X.N., Wu R.R., Zhang C.T., Lin C., Li Y.Y., Guo X.T., 2020. The occurrence and abundance of microplastics in surface water and sediment of the West River downstream, in the south of China. Sci. Total Environ. 756, 143857.

https://doi.org/10.1016/j.scitotenv.2020.143857. Jahan S., Strezov V., Weldekidan H., Kumar R., Kan T., Sarkodie S.A., He J., Dastjerdi B., Wilson S.P., 2019. Interrelationship of microplastic pollution in sediments and oysters in a seaport environment of the eastern coast of Australia. Sci. Total Environ. 695, 133924. https://doi.org/10.1016/j.scitotenv.2019.133924. Jambeck Jenna.R., Geyer R., Wilcox C., Siegler T.R., Perryman M., Andrady A., Narayan R., Law K.L., 2015. Plastic waste inputs from land into the ocean. Science. 347, 768-771. https://doi.org/10.1126/science.1260352. Jiang C.B., Yin L.S., Li Z.W., Wen X.F., Luo X., Hu S.P., Yang H.Y., Long Y.N., Deng B., Huang L.Z., Liu Y.Z., 2019. Microplastic pollution in the rivers of the Tibet Plateau. Environ. Pollut. 249, 91-98. https://doi.org/10.1016/j.envpol.2019.03.022. Kane I.A., Clare M.A., 2019. Dispersion, accumulation, and the ultimate fate of microplastics in deep-marine environments: A review and future directions. Front. Earth Sc-Switz. 7, 80.

https://doi.org/10.3389/feart.2019.00080. Kershaw, P., 2015. Sources, fate and effects of microplastics in the marine environment: A global assessment. International Maritime Organization. Klein S., Worch E., Knepper T.P., 2015. Occurrence and spatial distribution of microplastics in river shore sediments of the Rhine-main area in Germany. Environ. Sci. Technol. 49, 6070-6076.

https://doi.org/10.1021/acs.est.5b00492. Koelmans A.A., Nor N.H.M., Hermsen E., Kooi M., Mintenig S.M., De France J., 2019. Microplastics in freshwaters and drinking water: Critical review and assessment of data quality. Water Res. 155, 410-422. https://doi.org/10.1016/j.watres.2019.02.054. Kanhai L.K., Johansson C., Frias J.P.G.L., Gardfeldt K., Thompson R.C., O'Connor I., 2019. Deep sea sediments of the Arctic central basin: A potential sink for microplastics. Deep-Sea Res. Pt I. 145, 137-142. https://doi.org/10.1016/j.dsr.2019.03.003. Law K.L., Thompson R.C., 2014. Microplastics in the seas. Science. 345, 144-145. https://doi.org/10.1126/science.1254065. Lenaker P.L., Baldwin A.K., Corsi S.R., Mason S.A., Reneau P.C., Scott J.W., 2019. Vertical distribution of microplastics in the water column and surficial sediment from the Milwaukee River basin to Lake Michigan. Environ. Sci. Technol. 53, 1222712237. https://doi.org/10.1021/acs.est.9b03850. Leslie H.A., Brandsma S.H., van Velzen M.J.M., Vethaak A.D., 2017. Microplastics en route: Field measurements in the Dutch river delta and Amsterdam canals, wastewater treatment plants, North Sea sediments and biota. Environ. Int. 101, 133-142. https://doi.org/10.1016/j.envint.2017.01.018. Li C.C., Gan Y.D., Dong J.Y., Fang J.H., Chen H., Quan Q., Liu J., 2020. Impact of microplastics on microbial community in sediments of the Huangjinxia ReservoirWater source of a water diversion project in western China. Chemosphere. 253, 126740. https://doi.org/10.1016/j.chemosphere.2020.126740. Li L., Geng S.X., Wu C.X., Song K., Sun F.H., Visvanathan C., Xie F.Z., Wang Q.L., 2019. Microplastics contamination in different trophic state lakes along the middle and lower reaches of Yangtze River basin. Environ. Pollut. 254, 112951. https://doi.org/10.1016/j.envpol.2019.07.119. Lima A.R.A., Barletta M., Costa M.F., 2015. Seasonal distribution and interactions between plankton and microplastics in a tropical estuary. Estuar. Coast. Shelf S. 165, 213-225. https://doi.org/10.1016/j.ecss.2015.05.018. Lin L., Zuo L.Z., Peng J.P., Cai L.Q., Fok L., 
Yan Y., Li H.X., Xu X.R., 2018. Occurrence and distribution of microplastics in an urban river: A case study in the Pearl River along Guangzhou City, China. Sci. Total Environ. 644, 375-381.

https://doi.org/10.1016/j.scitotenv.2018.06.327. Mao R.F., Hu Y.Y., Zhang S.Y., Wu R.R., Guo X.T., 2020. Microplastics in the surface water of Wuliangsuhai Lake, northern China. Sci. Total Environ. 723, 137820. https://doi.org/10.1016/j.scitotenv.2020.137820. Martins J., Sobral P., 2011. Plastic marine debris on the Portuguese coastline: A matter of size? Mar. Pollut. Bull. 62, 2649-2653.

https://doi.org/10.1016/j.marpolbul.2011.09.028. MERI, 2015. Marine and Environmental Research Institute. Guide to microplastic identification. University of Florida. Muller G., 1969. Index of geoaccumulation in sediments of the Rhine River. Geojournal. 2, 108-118. Napper I.E., Thompson R.C., 2016. Release of synthetic microplastic plastic fibres from domestic washing machines: Effects of fabric type and washing conditions. Mar. Pollut. Bull. 112, 39-45.

https://doi.org/10.1016/j.marpolbul.2016.09.025. Narmadha, V.V., Jose J., Patil S., Farooqui M.O., Srimuruganandam B., Saravanadevi S., Krishnamurthi K., 2020. Assessment of microplastics in roadside suspended dust from urban and rural environment of Nagpur, India. Int. J. Environ. Res. 14, 629-640. https://doi.org/10.1007/s41742-020-00283-0. Ockelford A., Cundy A., Ebdon J.E., 2020. Storm response of fluvial sedimentary microplastics. Sci. Rep-UK. 10, 1865. https://doi.org/10.1038/s41598-020-58765-2. Pazos R.S., Bauer D.E., Gomez N., 2018 Microplastics integrating the coastal planktonic community in the inner zone of the Rio de la Plata estuary (South America). Environ. Pollut. 243, 134-142.

https://doi.org/10.1016/j.envpol.2018.08.064. Peng G.Y., Zhu B.S., Yang D.Q., Su L., Shi H.H., Li D.J., 2017. Microplastics in sediments of the Changjiang estuary, China. Environ. Pollut. 225, 283-290.

https://doi.org/10.1016/j.envpol.2016.12.064. Peters C.A., Hendrickson E., Minor E.C., Schreiner K., Halbur J., Bratton S.P., 2018. Pyr-GC/MS analysis of microplastics extracted from the stomach content of benthivore fish from the Texas Gulf Coast. Mar. Pollut. Bull. 137, 91-95.

https://doi.org/10.1016/j.marpolbul.2018.09.049. Su L., Xue Y.G., Li L.Y., Yang D.Q., Kolandhasamy P., Li D.J., Shi H.H., 2016. Microplastics in Taihu Lake, China. Environ. Pollut. 216, 711-719.

http://doi.org/10.1016/j.envpol.2016.06.036. Sun J., Dai X.H., Wang Q.L., Loosdrecht M.C.M. Ni B.J., 2019. Microplastics in wastewater treatment plants: Detection, occurrence and removal. Water Res. 152, 21-37. https://doi.org/10.1016/j.watres.2018.12.050. Sundt, P., Schulze P.E., Syversen F., 2014. Sources of microplastic-pollution to the marine environment. Mepex for the Norwegian Environment Agency. 86. Thompson, R.C., Olsen Y., Mitchell R.P., Davis A., Rowland S.J., John A.W.G., McGonigle D., Russell A.E., 2004. Lost at sea: Where is all the plastic? Science (Washington). 304, 838. https://doi.org/10.1126/science.1094559. Tong H.Y., Jiang Q.Y., Hu X.S., Zhong X.C., 2020. Occurrence and identification of microplastics in tap water from China. Chemosphere. 252, 126493.

https://doi.org/10.1016/j.chemosphere.2020.126493. Uddin S., Fowler S.W., Saeed T., 2020. Microplastic particles in the Persian/Arabian Gulf-A review on sampling and identification. Mar. Pollut. Bull. 154, 111100. https://doi.org/10.1016/j.marpolbul.2020.111100. Unice K.M., Weeber M.P., Abramson M.M., Reid R.C.D., van Gils J.A.G., Markus A.A., Vethaak A.D., Panko J.M., 2019. Characterizing export of land-based microplastics to the estuary-Part II: Sensitivity analysis of an integrated geospatial microplastic transport modeling assessment of tire and road wear particles. Sci. Total Environ. 646, 1650-1659. https://doi.org/10.1016/j.scitotenv.2018.08.301. Vaughan R., Turner S.D., Rose N.L., 2017. Microplastics 
in the sediments of a UK urban lake. Environ. Pollut. 229, 10-18. https://doi.org/10.1016/j.envpol.2017.05.057. Vianello A., Boldrin A., Guerriero P., Moschino V., Rella R., Sturaro A., Da Ros L., 2013. Microplastic particles in sediments of lagoon of Venice, Italy: First observations on occurrence, spatial patterns and identification. Estuar. Coast. Shelf S. 130, 54-61. https://doi.org/10.1016/j.ecss.2013.03.022. Wagner M., Lambert S., 2018. Freshwater microplastics: Emerging environmental contaminants? Springer Nature. https://doi.org/10.1007/978-3-319-61615-5. Wagner M., Scherer C., Alvarez-Munoz D., Brennholt N., Bourrain X., Buchinger S., Fries E., Grosbois C., Klasmeier J., Marti T., Rodriguez-Mozaz S., Urbatzka R., A. Vethaak D., Winther-Nielsen M., Reifferscheid G., 2014. Microplastics in freshwater ecosystems: What we know and what we need to know. Environ. Sci. Eur. 26, 1-9. https://doi.org/10.1186/s12302-014-0012-7. Wang J.D., Peng J.P., Tan Z., Gao Y.F., Zhan Z.W., Chen Q.Q., Cai L.Q., 2017. Microplastics in the surface sediments from the Beijiang River littoral zone: Composition, abundance, surface textures and interaction with heavy metals. Chemosphere. 171, 248-258. https://doi.org/10.1016/j.chemosphere.2016.12.074. Wen X.F., Du C.Y., Xu P., Zeng G.M., Huang D.L., Yin L.S., Yin Q.D., Hu L., Wan J., Zhang J.F., Tan S.Y., Deng R., 2018. Microplastic pollution in surface sediments of urban water areas in Changsha, China: Abundance, composition, surface textures. Mar. Pollut. Bull. 136, 414-423. https://doi.org/10.1016/j.marpolbul.2018.09.043. Woodall L.C., Sanchez-Vidal A., Canals M., Paterson G.L.J., Coppock R., Sleight V., Calafat A., Rogers A.D., Narayanaswamy, B.E., Thompson, R.C., 2014. The deep sea is a major sink for microplastic debris. Roy. Soc. Open Sci. 1, 140317. https://doi.org/10.1098/rsos.140317. Wu P.F., Tang Y.Y., Dang M., Wang S.Q., Jin H.B., Liu Y.S., Jing H., Zheng C.M., Yi S.P., Cai Z.W., 2020. Spatial-temporal distribution of microplastics in surface water and sediments of Maozhou River within Guangdong-Hong Kong-Macao Greater Bay Area. Sci. Total Environ. 717, 135187. https://doi.org/10.1016/j.scitotenv.2019.135187. Xue B.M., Zhang L.L., Li R.L., Wang Y.H., Guo J., Yu K.F., Wang S.P., 2020. Underestimated microplastic pollution derived from fishery activities and "Hidden" in deep sediment. Environ. Sci. Technol. 54, 2210-2217.

https://doi.org/10.1021/acs.est.9b04850. Yin L.S., Jiang C.B., Wen X.F., Du C.Y., Zhong W., Feng Z.Q., Long Y.N., Ma Y., 2019. Microplastic pollution in surface water of urban lakes in Changsha, China. Int. J. Env. Res. Pub. He. 16, 1650. https://doi.org/10.3390/ijerph16091650. Zhang B., Wu D., Yang X., Teng J., Liu Y.L., Zhang C., Zhao J.M., Yin X.N., You L.P., Liu Y.F., Wang Q., 2019. Microplastic pollution in the surface sediments collected from Sishili Bay, North Yellow Sea, China. Mar. Poll. Bull. 141, 9-15. https://doi.org/10.1016/j.marpolbul.2019.02.021. Zhang K., Gong W., Lv J.Z., Xiong X., Wu C.X., 2015. Accumulation of floating microplastics behind the Three Gorges Dam. Environ. Pollut. 204, 117-123. https://doi.org/10.1016/j.envpol.2015.04.023. Zhang K., Shi H.H., Peng J.P., Wang Y.H., Xiong X., Wu C.X., Lam P.K.S., 2018. Microplastic pollution in China's inland water systems: A review of findings, methods, characteristics, effects, and management. Sci. Total Environ. 630, 1641-1653.

https://doi.org/10.1016/j.scitotenv.2018.02.300. Zhang Q., Xu E.G., Li J.N., Chen Q.Q., Ma L.P., Zeng E.Y., Shi H.H., 2020. A review of microplastics in table salt, drinking water, and air: Direct human exposure. Environ. Sci. Technol. 54, 3740-3751. https://doi.org/10.1021/acs.est.9b04535. Zhou Q., Tu C., Fu C.C., Li Y., Zhang H.B., Xiong K.X., Zhao X.Y., Li L.Z., Waniek J.J., Luo Y.M., 2020. Characteristics and distribution of microplastics in the coastal mangrove sediments of China. Sci. Total Environ. 703, 134807. https://doi.org/10.1016/j.scitotenv.2019.134807. 
Figures

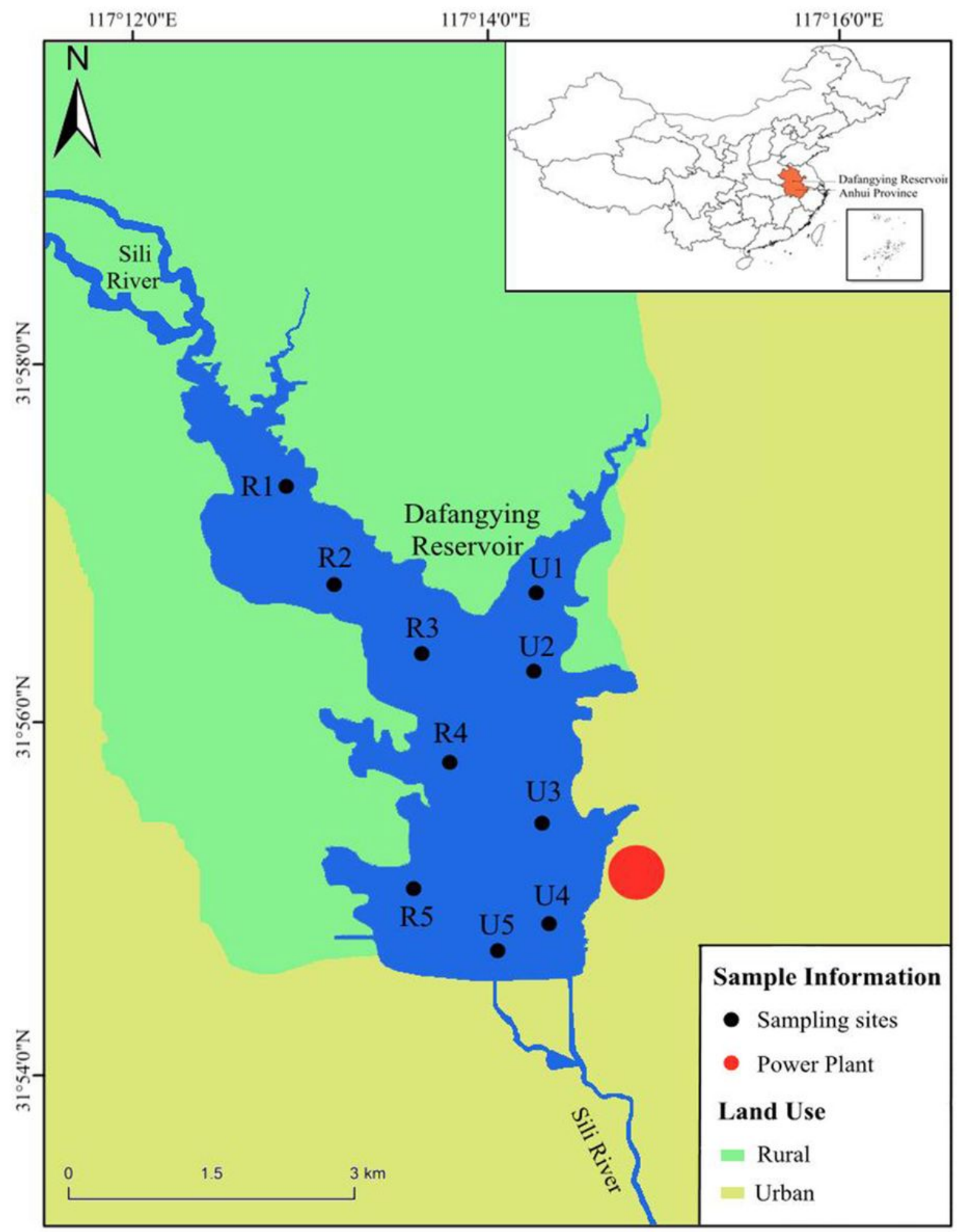

Figure 1

Geographic locations, sampling sites and land use of the Dafangying Reservoir. 


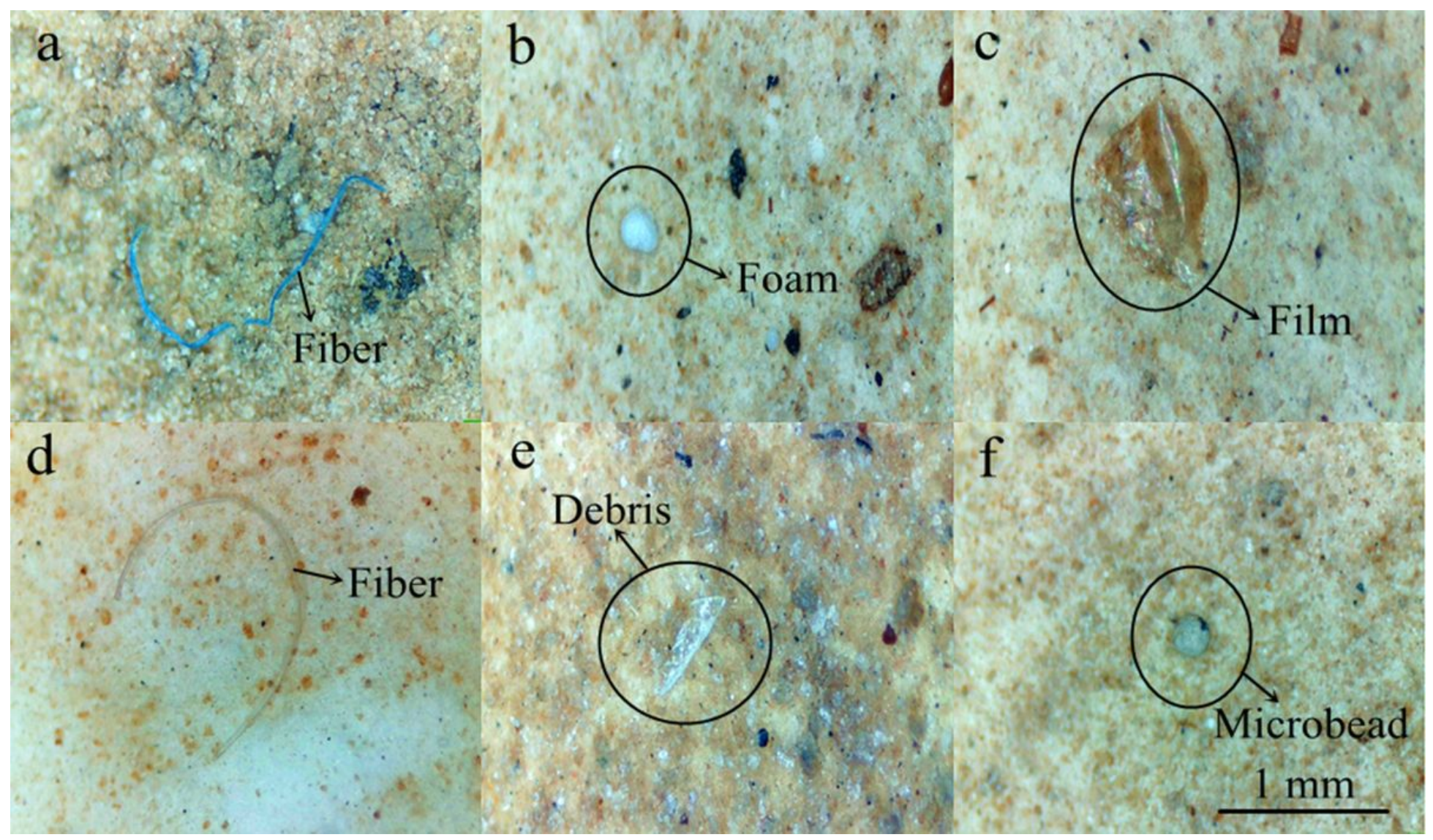

Figure 2

Examples of microplastics with different shapes (a, Fiber; b, Foam; c, Film; d, Fiber; e, Debris; f, Microbead). 

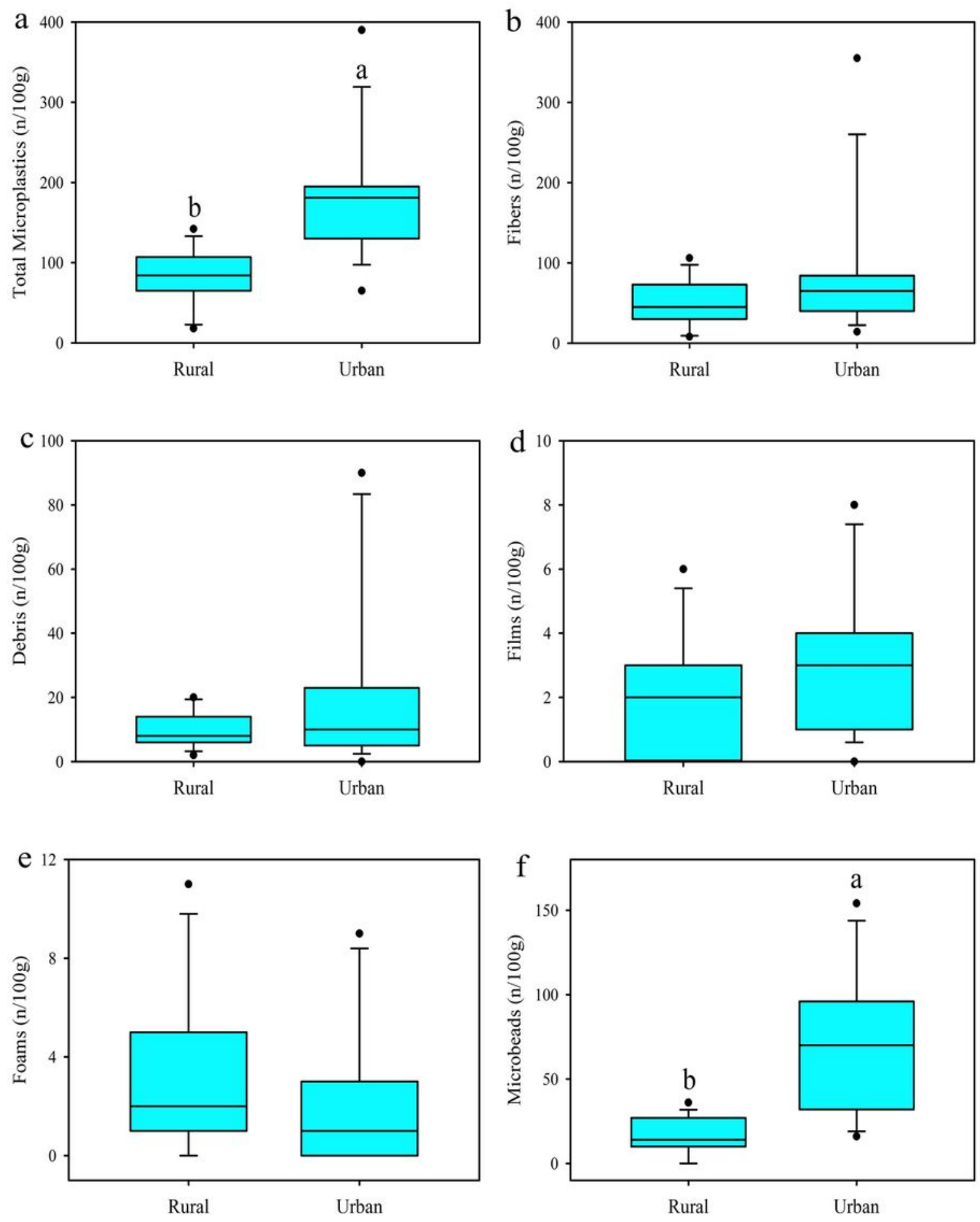

Figure 3

The abundance of total microplastics (a), fibers (b), debris (c), films (d), foams (e) and microbeads (f) between rural and urban sites (The solid horizontal lines for each box from top to bottom indicate the maximum value, $75 \%$ quartile, median, $25 \%$ quartile, and minimum value, respectively; the black dots are outliers). 


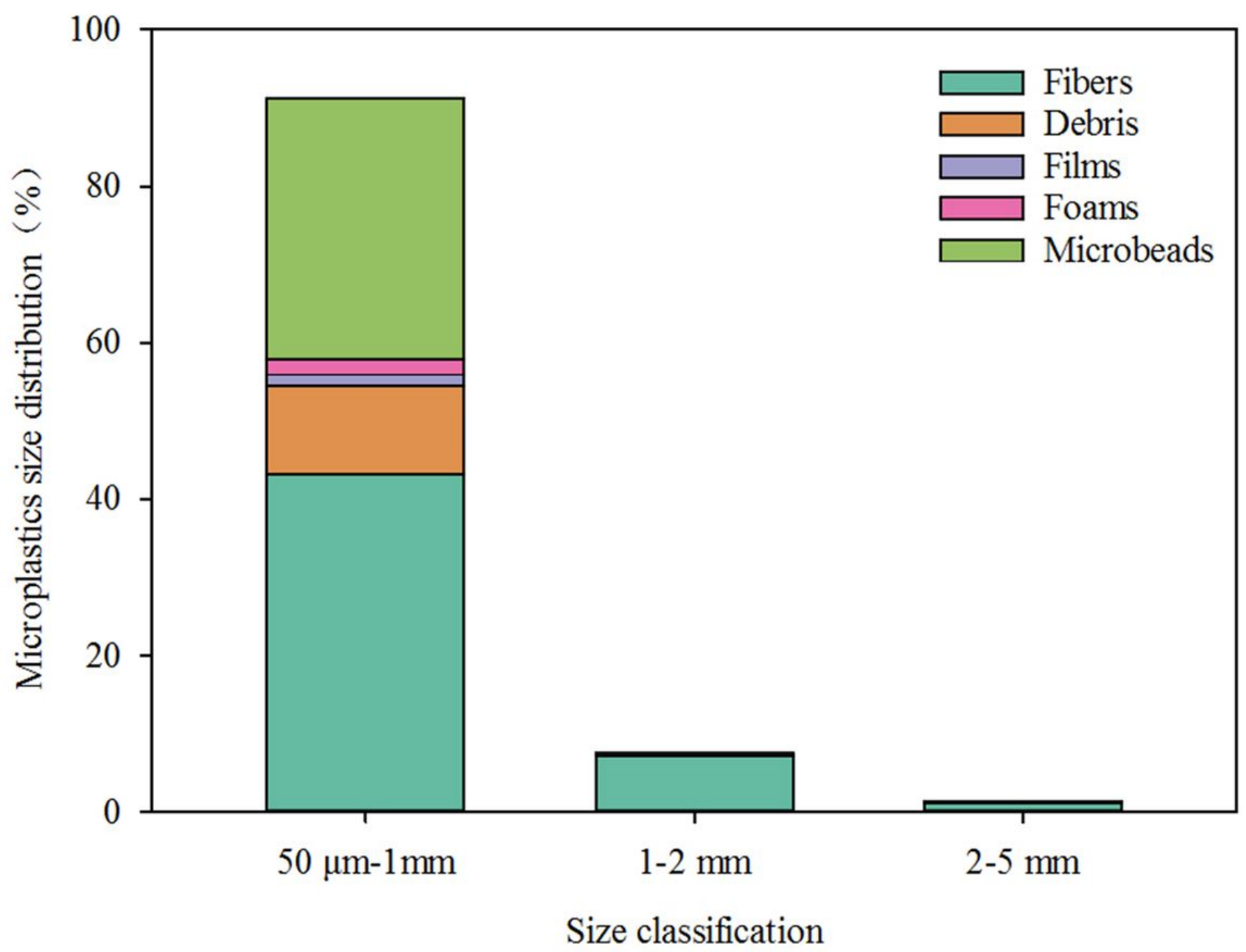

Figure 4

Size distribution of microplastics in sediments of the Dafangying Reservoir. 

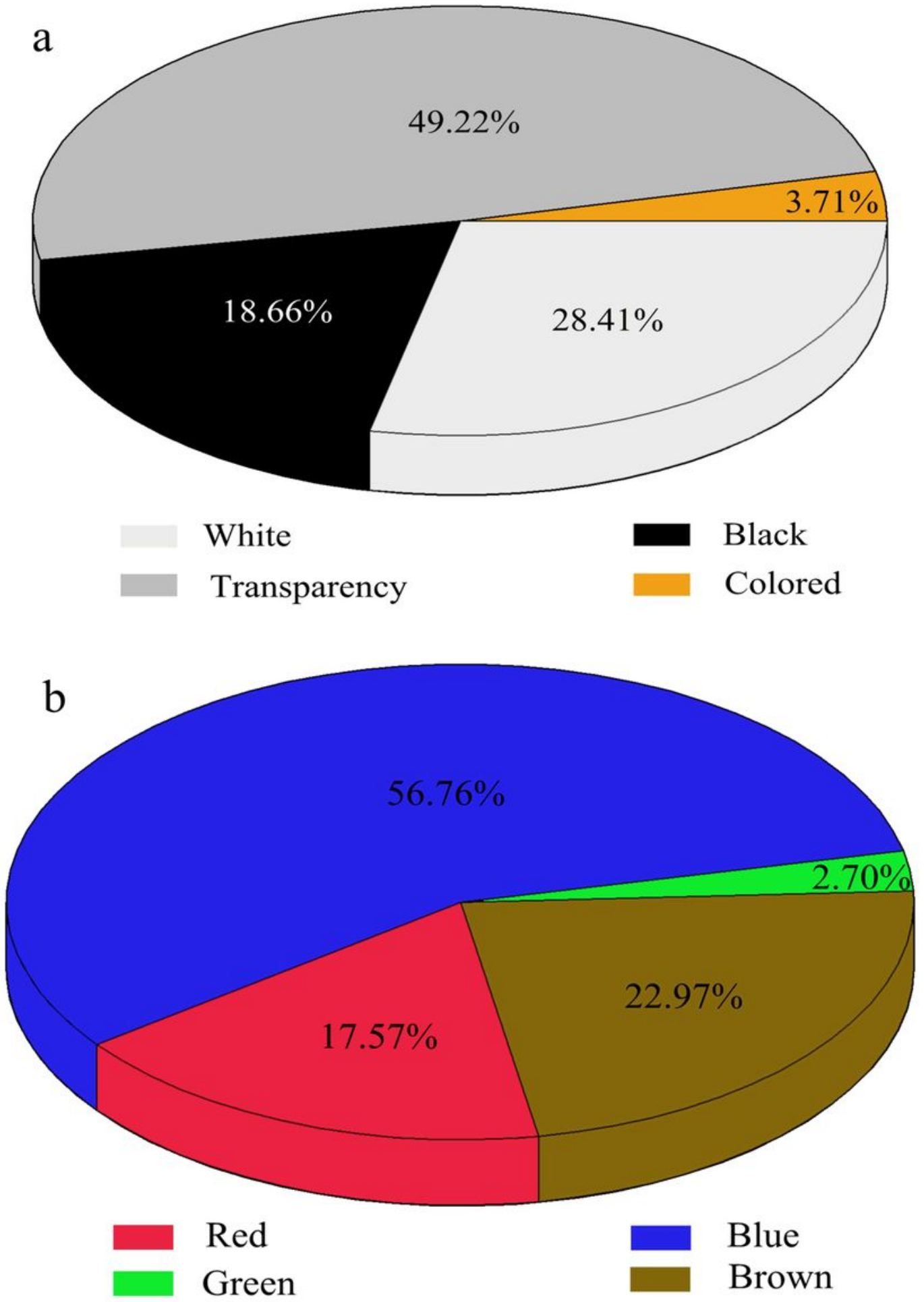

Figure 5

Color distribution of microplastics in sediments (b, colored include red, blue, brown and green). 


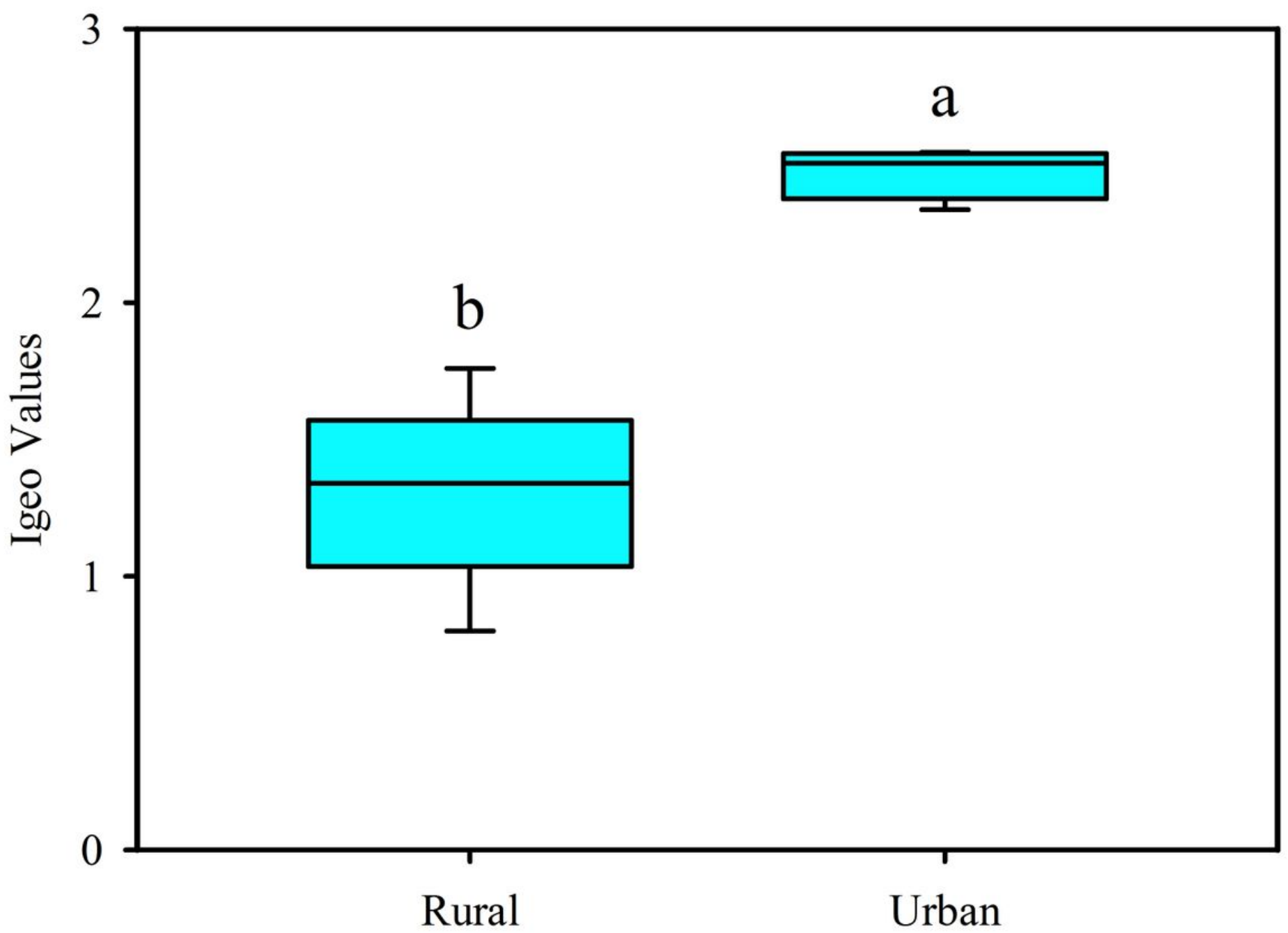

Figure 6

The Igeo values between rural and urban sites (The solid horizontal lines for each box from top to bottom indicate the maximum value, $75 \%$ quartile, median, $25 \%$ quartile, and minimum value, respectively). 